\title{
Kant's Causal Power Argument against Empirical Affection
}

\author{
Jonas Jervell Indregard
}

\begin{abstract}
:
A well-known trilemma faces the interpretation of Kant's theory of affection, namely whether the objects that affect us are empirical, noumenal, or both. I argue that according to Kant, the things that affect us and cause representations in us are not empirical objects. I articulate what I call the Causal Power Argument, according to which empirical objects cannot affect us because they do not have the right kind of power to cause representations. All the causal powers that empirical objects have are moving powers, and such powers can only have spatial effects. According to Kant, however, the representations that arise in us as a result of the affection of our sensibility are non-spatial. I show that this argument is put forward by Kant in a number of passages, and figures as a decisive reason for rejecting empirical affection and instead endorsing affection by the things in themselves.
\end{abstract}

\section{KEYWORDS:}

affection, causality, Immanuel Kant, motion, power, regulative function, representation, space

Kant claims in the $\boldsymbol{K}_{r} \boldsymbol{V}$ that objects can be given to us only if they affect us (cf. A19/B33).' This claim has generated a great amount of controversy. The source of the controversy is Kant's distinction between two senses of the term 'object', namely the object as appearance and the object as thing in itself (cf. Bxxvii). This gives rise to the question: Which sense(s) of the term is Kant referring to when claiming that objects must affect us?

Three basic positions have been advocated:

Noumenal affection (NA): The affecting objects are things in themselves. 
Empirical affection (EA): The affecting objects are appearances.

Double affection (DA): The affecting objects include both things in themselves and

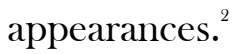

No consensus has been reached concerning which of these positions represent Kant's actual view, and each of them still has defenders within contemporary Kant scholarship. ${ }^{3}$ In this article, I will examine a relatively neglected argument against empirical affection, and thus against both EA and DA (since DA requires empirical as well as noumenal affection). Kant puts forward this neglected argument on several occasions, and affirms NA as a result of accepting it.

The argument can be termed the 'Causal Power Argument'. It takes as its starting point a feature of Kant's account of causal relations. Commentators such as Langsam, Langton, and Watkins have pointed out that Kant conceives of causal relations as grounded in the causal powers [Kräfte] of things. ${ }^{4}$ The Causal Power Argument then turns on Kant's view, expounded in the Critical period and expressed most clearly in $M A N$, concerning the kind of causal powers that empirical outer objects, i.e., appearances in space, can have. ${ }^{5}$

According to Kant, they do not have the kind of causal power required in order to cause representations. They only have moving powers, i.e., powers to cause changes in spatial relations. Representations, however, are not located in space at all. This implies that there is no causal affection relation between us, understood as representing subjects, and outer empirical objects. ${ }^{6}$

The Causal Power Argument can be arranged in the following manner: 
1. Affection is a causal relation between object and subject, the effect of which is representations.

2. Causal relations require suitable causal powers.

3. Empirical objects have no other causal powers than moving powers.

4. Moving powers are powers to cause changes in spatial relations.

5. Representations do not stand in spatial relations.

6. (From 4, 5) Moving powers cannot cause representations.

7. (From 6, 3) Empirical objects have no causal power to cause representations.

8. (From 7, 2, 1) Empirical objects do not affect us.

In the following I will concentrate on presenting the Causal Power Argument and showing that it was put forward and advocated by Kant. One can reasonably doubt whether Kant should have held its premises, and my aim is merely to show that he indeed did hold them. For this reason as well as others, the argument presented here falls short of a full-fledged defence of NA: As is well known, there are also problems concerning the intelligibility and consistency of noumenal affection, chief among them the problem of how to make sense of causation in a noumenal context. Recent scholarship has seen promising attempts to tackle this issue, and I will not contribute further to this task here.?

My paper is divided into six sections. Section I explicates premises 1-2 of the Causal Power Argument and shows that Kant holds them, while section II does the same for premises 3-4. In section III, I first explain how 'representation' should be understood in premise 5 as well as in the rest of the argument, and then show that Kant holds this premise as well. In section IV, I show that Kant draws conclusions 6-8 from these premises, and that he moreover concludes in favor of NA as a result of accepting the Causal Power Argument. 
Finally, section $\mathbf{V}$ considers two strategies for dealing with passages in which Kant seems to affirm empirical affection, while section VI summarizes the argument of the paper.

\section{I: Affection and Causal Power}

Premise 1 - Affection is a causal relation between object and subject, the effect of which is representations - is relatively uncontroversial. Kant's initial statements concerning affection in $K r V$ regard affection as a relation between object and subject, the effect of which is representations, for instance by characterizing sensibility as 'the capacity (receptivity) to acquire representations through the way in which we are affected by objects' (A19/B33, cf. A51/B75).

It is occasionally denied that the affection relation is causal. Allison, for instance, suggests that '[a]ffection, as Kant construes it, is clearly an epistemic rather than a causal relation, albeit one that is inextricably connected with the latter' ${ }^{8}$ The majority of commentators, however, hold that affection is causal. ${ }^{9}$ This is not so surprising, as the causal reading has strong textual support: Sensations appear to arise causally from affection, as the 'effect [Wirkung] of an object on the capacity for representation, insofar as we are affected by it' (A19-20/B34, my italics). Similarly, the Prolegomena speaks of the 'representations which [objects] produce [wirken] in us because they affect [afficiren] our senses' (Prol, 4: 289, my italics). Moreover, Kant often shifts seemingly indiscriminately between 'affection' and 'influence' (which is clearly a causal notion, cf. e.g. B111; $M M r, 29: 823$ ); in the sentence just following the one quoted from Prolegomena, Kant refers to 'the representations which 
[the objects'] influence [Einfluß] on our sensibility provides for us' (Prol, 4: 289, my italics; cf. also B154).

If one were to deny that affection is a causal relation, a modified version of the Causal Power Argument would still retain force. Chopping off premise 1 and conclusion 8 leaves an argument that still rules out any causal relation between empirical objects and the representing subject. While it would then not preclude empirical affection as a non-causal relation between empirical objects and the subject, as far as I am aware no commentator has defended such a view. Allison, for instance, asserts quite the opposite, namely a causal but non-affective relation between empirical object and subject: 'Kant can perfectly well speak of a causal (as opposed to an affective) relation between phenomena and the human mind' (2004: 67). This claim is still contradicted by a Causal Power Argument reduced to steps 2-7.

Crucial to the Causal Power Argument is the notion of a causal power, first introduced in premise 2: Causal relations require suitable causal powers. Recent commentators have argued that Kant's account of causality cannot be understood as an event-event model, but must be understood in terms of the causal powers of objects. Eric Watkins, perhaps the main figure responsible for bringing the importance of causal powers to light, summarizes: 'Causality occurs if one substance determines the state of another by actively exercising its causal powers according to their natures and circumstances' (2005: 13). ${ }^{10}$ Causal power should be construed, according to Watkins, as the 'causality of the cause', i.e., 'that aspect of a substance by means of which it can be a cause' (2005: 249). Here I will briefly present textual grounds for thinking that Kant's account of causal relations must include reference to causal powers. 
Kant often conceptually subordinates power 'under the category of causality' (A82/B108; cf. Prol 4: 257; $\ddot{U E}, 8: 223)$. In his discussion of causality in the Second Analogy, Kant says that 'causality leads to the concept of action, this to the concept of power [Kraft], and thereby to the concept of substance' (A204/B249; cf. A82/B108; ML, 28: 564). ${ }^{11}$

In the Analogy, Kant further claims that 'all alteration is (...) possible only through a continuous action of causality' (A208/B254), and that the ultimate agent of such an 'action of causality' must be a persisting substance: 'Actions are always the primary ground of all change of appearances, and therefore cannot lie in a subject that itself changes (...). [O]n this account action, as a sufficient empirical criterion, proves substantiality' (A205/B250). And according to Kant, the causality of a substance, exercised in such actions, is its power: 'The causality of a substance (...) is called "power"' (A648/B676). Thus, he says that

$[\mathrm{h}]$ ow in general anything can be altered (...) we have a priori not the least concept. For this acquaintance with actual powers is required, which can only be given empirically, e.g., acquaintance with moving powers, or what comes to the same thing, with certain successive appearances (as motions) which indicate such powers (A206-207/B252; cf. B66-67).

The reason why successive appearances 'indicate' powers is that as alteration, this succession is possible only through an action of causality, i.e., through the exercise of a cause's causal power.

This reading is supported by Kant's metaphysics lectures, wherein he states: 'Action is the determination of the power of a substance as the cause of a certain accident' $\left(M L_{2}, 28: 565\right)$, 
and '[a]ll efficient causes <causae efficientes> are thus determinations of powers' $(\boldsymbol{M M r}, 29$ : 845, cf. 29: 840-841; $\left.M L_{2}, 28: 572\right)$. And in the $M A N$, Kant explicates all causal relations between outer objects in terms of their attractive and repulsive powers ( $M A N, 4: 496 \mathrm{f}$, see esp. 4: 499).

A causal power is suitable insofar as it can serve as a ground for the right kind of effect: 'The relation of a substance to accidents insofar as it contains their ground is causality, and insofar as it contains a general ground for a certain kind of accidents, is power' $\left(M V_{O}, 28\right.$ : 431). Attractive and repulsive power, for instance, is suitable as grounds for motion towards and motion away from the locus of power, respectively.

To summarize the result of this section: Affection should be seen as a causal relation involving a suitable causal power of an object. The pertinent issue for our investigation then becomes: Does the empirical object have powers suitable for affecting the subject and thereby causing representations?

\section{II: Empirical Objects and Moving Powers}

Out of the premises of the Causal Power Argument, premise 3 - empirical objects have no other powers than moving powers - is in many ways the most surprising. The causal power model of causation is something Kant held throughout his life, beginning from his very first work on the vis viva controversy in 1747. But in that work Kant argued - against preestablished harmony and occasionalist views - that mind-body interaction was perfectly conceivable, since the general notion of active power allowed matter to have other such powers than merely the power to cause motion. ${ }^{12}$ Once we have a suitably general 
understanding of power along the lines of 'the causality of the cause', there is nothing preventing us from conceiving of matter as having a fundamental power to cause representations. $^{13}$

As late as the Metaphysik $L_{l}$ lectures of the mid-1770s, Kant argues that while we cannot comprehend a priori the powers by means of which soul and body interact, we can nonetheless experience them:

\begin{abstract}
We cannot have insight through reason into the reciprocal determination between thinking and willing and between moving. (...) But through experience we can comprehend it; and indeed this applies not here alone, but rather all basic powers are given to us through experience, and none can be comprehended through reason $\left(M L_{l}, 28: 279\right.$, cf. 28: 259-261; R5457 (1776-78), 18: 187).
\end{abstract}

Kant here conceives the ability to cause representations as a basic power of bodies, experienced by us, and no more incomprehensible than other basic powers of bodies, like the powers of attraction and repulsion.

At some point between these lectures and $K_{r} V$, however, Kant came to retract the claim that we experience the basic power of bodies to cause representations in our soul; instead he came to hold that the only powers of bodies that we experience are their moving powers, and thus premise 3 . This is expressed most clearly in the $M A N$, as I will show, where Kant develops an account of the most fundamental powers of outer, empirical objects in space. 
Premise 4 expresses what such moving powers are: Moving powers are powers to cause changes in spatial relations.

Kant's account of the two fundamental powers of outer objects is well known. The account occupies the second section of the $M A N$, the Dynamics. In the Dynamics, Kant considers matter insofar as it fills a space. This requires reference not merely to its motion, but to the cause of its motions, namely its moving powers [Bewegungskräfte]: 'It (...) adds a property relating as cause to an effect, namely, the power to resist a motion within a certain space' (MAN, 4: 496). This is repulsive power, to which we must add a second fundamental power, namely attractive power (cf. $M A N, 4: 508 f$.).

What is less often noted or discussed is that Kant claims to provide a complete account of the fundamental powers of matter. He holds that all moving powers are ultimately reducible to the two fundamental powers (cf. MAN, 4: 499, 4: 532). More importantly, he states that matter has no other powers than moving powers:

The general principle of the dynamics of material nature is that everything real in the objects of outer senses, which is not merely a determination of space (place, extension, and figure) must be viewed as moving power (...). [T] he concept of matter is reduced to nothing but moving powers, and one could not expect anything else, since no activity or change can be thought in space except mere motion (MAN, 4: 523-524).

The empirical objects of premise 3 are the 'objects of outer senses', and Kant here states that 'everything real' in them is moving power. $M A N$ contains the metaphysical 
foundations of the science of 'the objects of the outer senses, [i.e.,] extended nature' (MAN, 4: 467); and as we can now see, among its principles is that these objects have only one kind of power, namely moving power.

In $K r V$, Kant accordingly claims that the 'substance that appears in space' possesses only moving powers:

We know [kennen] substance in space only through powers that are efficacious in it, whether in drawing others to it (attraction) or in preventing penetration of it (repulsion and impenetrability); we are not acquainted with [kennen nicht] other properties constituting the concept of the substance that appears in space and which we call matter (A265/B321).

Similarly, he states that through outer intuition we cognize only moving powers: 'Everything in our cognition that belongs to [outer] intuition (...) contains nothing but mere relations, of places in one intuition (extension), alteration of places (motion), and laws in accordance with which this alteration is determined (moving powers)' (B66-67). In 1786 Kant also writes: '[T]he thing in space, apart from there being space in it (...), shows no further effect than movement (...), consequently no other power or passive property than moving power and movability (alteration of external relations)' (EB, 8: 153; cf. also $M M r$, 29: 908, 29: 929, 29: 934).

Could it be that while we do not know other powers than moving powers, empirical objects may still have other powers? Kant considers the possibility of making 'entirely new concepts of substances, of powers, and of interactions (...), without borrowing the example 
of their connection from experience' (A222/B269), but his estimation of the usefulness of such invented concepts is decidedly negative: '[O]ne would end up with nothing but figments of the brain, for the possibility of which there would be no indications at all' (A222/B269), since without being 'grounded in experience and its known laws, (...) it is an arbitrary combination of thoughts that, although it contains no contradiction, still can make no claim to objective reality' (A223/B270). As 'arbitrary combination of thoughts', empirical powers other than moving powers would remain a mere logical possibility, which does not suffice to challenge premise 3 - that would require at least the real possibility (and plausibly the real actuality) of such powers. ${ }^{14}$

One could still object to equating empirical objects with $M A N$ 's concept of matter, by arguing that life pertains to (some) empirical objects but not to matter as such. In $M A N$, Kant states that 'all matter, as such, is lifeless' (MAN, 4: 544), defining life as 'the faculty of a substance to determine itself to act from an internal principle, of a finite substance to change, and of a material substance [to determine itself] to motion or rest, as change of its state' (MAN, 4: 544). The 'internal principle' in question involves representation (cf. $M A N$, 4: 544; $\boldsymbol{M S}$, 6: 211; $\boldsymbol{M L}, 28: 594)$. $\boldsymbol{K} U$ speaks of an 'organized being' as

not a mere machine, for that has only a motive power, while the organized being possesses in itself a formative power [bildende Kraft], and indeed one that it communicates to the matter, which does not have it (it organizes the latter); thus it has a self-propagating formative power, which cannot be explained through the capacity for movement alone (that is, mechanism) (KU, 5: 374). 
If some empirical objects are living, organized beings, they have other powers than the moving powers that may be ascribed to matter as such. ${ }^{15}$

However, according to Kant we cannot objectively or constitutively ascribe life or formative power to empirical objects. The concept of natural end, that according to Kant underlies the notion of organized or living beings in nature, is

not a constitutive concept of the understanding or of reason, but (...) a regulative concept for the reflecting power of judgment, for guiding research into objects of this kind (...); not of course, for the sake of knowledge [Kenntnißs] of nature or of its original ground $(K U, 5$ : 375).

As a merely regulative concept (cf. $K U, 5: 379,5: 396$ ), it allows us to proceed as if (cf. $K U$, 5: 404, 5: 422) these objects have an 'internal principle' and power, but 'never justifies us in introducing into natural science a special kind of agency [ Wirkungsart] distinct from causality in accordance with merely mechanical laws of nature' $(K U, 5: 390)$, i.e., in accordance with moving powers. In other words, the objective reality of this concept can be established neither through experience nor through reason (cf. $K U, 5: 396)$. In accordance with premise 3, then, life and its accompanying powers are not, for Kant, validly ascribed to empirical (outer) objects (although we can validly proceed as if certain empirical objects are living).

Premise 4 can be established in two quick steps. First, Kant claims that moving powers are powers to cause motion: 'The cause of a motion is called a moving power' (MAN, 4: 497). 
Second, according to Kant the motion of an object is a change of its spatial relations:

'Motion of a thing is the change of its outer relations to a given space' $(\boldsymbol{M A N}, 4: 482){ }^{16}$

Thus moving powers are the causes of changes in a thing's outer relations (cf. $M M r, 29$ :

841). From these two steps, premise 4 - moving powers are powers to cause changes in spatial relations - can be concluded.

Above, we questioned whether the empirical object has suitable powers for causing representations. Having now found that all the powers of the empirical object are moving powers, the question is: Can moving powers cause representations?

\section{III: The Non-Spatiality of Representations}

This section is dedicated to the task of defending premise 5: Representations do not stand in spatial relations. Explicating this premise requires me to first specify the meaning of the term 'representations' as used in the premise, before I can proceed to present textual evidence for it.

I will not argue that in all senses of the term 'representation', they cannot stand in outer relations. Kant repeatedly claims that outer appearances, i.e., empirical objects in space, are representations, ${ }^{17}$ and that 'motion itself (hence also the matter that makes itself knowable through it) is a mere representation' (A387). In saying that representations do not stand in spatial relations (premise 5), I of course do not mean to say that matter and its motions do not stand in spatial relations. I will instead show that there is an important sense of the term 'representation' on which representations cannot stand in outer relations, and that it is this kind of representation that results from affection. I will call representation in this sense S- 
representation ( $\mathbf{S}$ for 'subjective'), and argue that it is S-representation that figures in premises 1, 5, 6, and 7 in the argument of the paper. This sense, I take it, is distinct from the sense in which motion and outer appearances can be considered representations, which we may call O-representation (for 'objective').

What are S-representations? Pre-theoretically, S-representation is quite a straightforward notion to grasp: The private stream of successive mental states or acts such as thoughts, feelings, perceptions, etc., that goes on in my mind (as opposed to yours) and that is only directly accessible to me, consists of S-representations. ${ }^{18}$ These are distinct from the outer appearances, i.e., empirical objects in space, which are relatively persistent and publicly accessible.

Kant adheres to this distinction, for instance in the Second Analogy, where he discusses the successive 'apprehension of the manifold in the appearance of a house' (A190/B235), a manifold he distinguishes from 'the manifold of this house itself' (A190/B235). In the manifold of the appearance, 'the representations of the parts succeed one another' (A189/B234); but when it comes to the manifold of the house itself, i.e., its parts, 'no one will concede' (A190/B235), including Kant, that they are successive. The successive apprehension of the manifold gives a succession of S-representations, while the parts of the house, as parts of an empirical object, are coexisting O-representations. This should indicate why I label S-representation as subjective: The house and its parts is objective, while our successive perceptions of its parts are subjective.

Given Kant's transcendental idealism, there is a tight relation between S-representations and O-representations; depending on one's reading of transcendental idealism as well as Kant's theory of perception, this relation can be cashed out in a variety of different ways. 
One suitably neutral and non-committal (for my purposes) way of cashing out the relation is to say that O-representations are represented by (some, actual or possible) Srepresentations. ${ }^{19}$ In any case, my interpretation hinges only on what I take it that any plausible Kant interpretation will have to admit, namely that S- and O-representations are different, and that their properties might diverge significantly (as in the above house example where the S-representations are successive, but the O-representations are coexistent).

While S-representations can clearly represent external relations in space (e.g. a house), the question is whether they themselves can be or stand in external relations in space. The latter, not the former, is needed if moving powers are to be the cause of S-representations (rather than the cause of what these S-representations represent).

There are many indications that S-representations are not themselves spatial: In the Aesthetic, Kant states that 'space, as the pure form of all outer intuitions, is limited as an a priori condition merely to outer intuitions', whereas 'all representations, whether or not they have outer things as their object, nevertheless as determinations of the mind belong to the inner state, while this inner state belongs under the formal condition of inner intuition, and thus of time' (A34/B50), and he often points out that only outer appearances are in space, whereas all appearances are in time; within our mind 'everything is in continual flux' since 'time, which is the only form of our inner intuition, has in it nothing abiding' (A381, my italics, cf. A107; R5653, 18: 307, R5655, 18: 314-315). The Refutation of Idealism also seems to presuppose the non-spatial and hence non-abiding nature of S-representations: Only given this presupposition would Kant's claim that the persisting thing required for time-determination 'cannot be an intuition in me' (Bxxxix) make sense..$^{20}$ 
More explicit denials that S-representations are spatial can also be found:

Extension, impenetrability, composition and motion - in short, everything our outer senses can transmit to us - are not thoughts, feelings, inclinations or decisions, and cannot contain them, as these are never objects of outer intuition (A358).

Looking beyond the $\boldsymbol{K} \boldsymbol{r} \boldsymbol{V}$, the Leningrad Reflexion states that '[i]t is impossible to think of representations as existing in space' $(L R, 27)$, and other reflections convey the same point: 'My representations cannot be outside me and an outer object of representations cannot be in me, for that would be a contradiction' (R6315, 18: 620; cf. R6312, 18: 612-613). Similar statements are found throughout the metaphysics lectures:

All determinations of the soul are ordered not according to space but rather merely according to time (ML, 28: 584).

All representations are something in us, and we cannot say that they are objects of the outer senses. But all matter is an object of the outer senses, and we can assume nothing of its inner representations. With matter we have nothing other than outer relations and alterations of outer relations $\left(\boldsymbol{M K}\right.$, 28: 759-760). ${ }^{21}$ 
These passages together constitute strong textual evidence that there is a sense of 'representation', namely what I have called S-representation, on which representations are 'inner determinations' (cf. A283/B339) which are not in space and do not stand in spatial relations. $^{22}$

In premise 1, the representations are sensations: 'The effect of an object on our capacity for representation, insofar as we are affected by it, is sensation' (A19-20/B34). Many of the characterizations that Kant gives of sensation indicate that it should be understood as Srepresentation: sensation is a 'merely subjective representation, by which one can only be conscious that the subject is affected' (B207), and 'refers to the subject as a modification of its state' (A320/B376). Moreover, Kant distinguishes sensation from the sensible properties of empirical objects, where these properties are as 'the real, which corresponds to it [i.e., the sensation] in the object (realitas phaenomenon)' (A165; cf. A20/B34, A581/B609, A723/B751). ${ }^{23}$ While the realitas phaenomenon might not be an S-representation, the sensation corresponding to it in the subject is. ${ }^{24}$

If S-representations were outer relations, they would have to be determinations of matter in space. A natural suggestion would be to conceive of S-representations as states of our sensory organs and/or our brain. ${ }^{25}$ Kant, however, refuses to go further than saying that to our empirical representations 'there can be assumed to correspond impressions [Eindrücke] in the brain' (SÖ, 12: 32n.). The impressions in the brain correspond to representations, rather than being representations. And elsewhere, Kant is clear that matter (including the brain) cannot have representations: 'All natural science rests on the proposition: that matter can have no representations' (MVo, 28: 449; cf. $\boldsymbol{M D}$, 28: 681; $\boldsymbol{M K}_{2}$, 28: 754, 28: 760). 


\section{IV: The Denial of Empirical Affection}

To recapitulate, the Causal Power Argument goes as follows (now with the sense of ‘representation’ specified as S-representation):

1. Affection is a causal relation between object and subject, the effect of which is Srepresentations.

2. Causal relations require suitable causal powers.

3. Empirical objects have no other causal powers than moving powers.

4. Moving powers are powers to cause changes in spatial relations.

5. S-representations do not stand in spatial relations.

6. (From 4, 5) Moving powers cannot cause S-representations.

7. (From 6, 3) Empirical objects have no causal power to cause S-representations.

8. (From 7, 2, 1) Empirical objects do not affect us.

In the preceding sections, I have argued that Kant held premises 1-5. In this section, I will present evidence that Kant himself drew conclusions 6-8. Some interpreters have noticed this evidence, but its rationale has hitherto been insufficiently appreciated, with for instance Hogan simply noting it as a 'remarkable point'. ${ }^{26}$ Seeing that Kant accepts and appeals to premises 1-5 - sometimes more, sometimes less explicitly so - helps us understand the reasoning underlying these claims.

Premises 1 and 2 are general claims that one would not expect to see in this argumentative context. Premises 3-5, however, can be found in more or less truncated forms. The following passage from an early 1790s metaphysics lecture is among the more elaborate: 
Bodies as bodies cannot act upon the soul and vice versa, because bodies cannot have any relations at all to a thinking being. The outer relations in which a body stands with a substance is only in space, thus this substance must also be in space, therefore a body. Locations are pure relations. Alterations of the locations is alteration of the relations. The filling of space, the figure of the body, i.e., the alteration of the boundaries are sheer relations. With the soul we can name only what is altered internally, but these are not relations, but rather only accidents <accidentia>, e.g., representations, etc. Since the relation of the body consists only in space, then it cannot be the ground of the inner determinations, e.g., of the representations $(\boldsymbol{M K}$, 28: 758$)$.

Premise 5 - that S-representations do not stand in spatial relations - is discernable in the contrast between 'outer relations' in space and what is 'altered internally', and the claim that 'these [the 'representations, etc.'] are not relations'. Premises 3 and 4 are less evident; thus it is not quite clear from the passage precisely why 'bodies as bodies cannot act upon the soul', since this cannot be deduced from premise 5 (along with 1 and 2) alone. However, the claim that 'the relation of the body consists only in space' can be taken to also include, importantly, its powers, since Kant often includes moving powers under the broad label of outer 'relations' (cf. e.g. B66-67). This explains why Kant goes on to say of the body that 'it cannot be the ground of the inner determinations'. For, as he says just after: 'Between motions and representations there is not the least connection' $\left(\boldsymbol{M} \boldsymbol{K}_{2}, 28: 759\right)$. 
Kant goes on to draw a further conclusion not part of the Causal Power Argument, namely, the affirmation of NA. The passage continues as follows:

The body as phenomenon is not in community with the soul, but rather the substance distinct from the soul, whose appearance is called body. This substrate of the body is an outer determining ground of the soul, but how this interaction $<$ commercium $>$ is constituted, we do not know (...) If we say the intelligible of the body acts upon the soul, then this means this outer body's noumenon determines the soul $\left(M K_{2}, 28: 758-759\right)$.

Supposing that there are only three available alternatives for explicating the affection relation, we can see why Kant would draw this further conclusion: If empirical affection is denied, then, since both EA and DA requires empirical affection, NA is the only remaining alternative.

In a different metaphysics lecture from 1792-93, Kant first states that:

We can never obtain representations from the motions of matter, thus materialism has no influence on psychology (...) with matter we always find nothing but outer relations $(M D, 28: 682)$. 
Again, this should be read as short-hand for the claim that we can never obtain representations from the motions of matter, or from its moving powers. A bit later in the lecture, Kant repeats this thought, in explaining why bodies as bodies cannot affect the soul:

Bodies as bodies cannot effect the soul because no relation is possible here. The outer relation in which a body stands with another substance can be thought only in space. But the concepts of body and matter themselves contain sheer relations. But with the internal alterations there occur not merely relations, but rather accidents (...). Bodies are phenomena, their substrate, - the intelligible noumenon, and it is this which has influence on the soul - one cannot explain this $(M D, 28$ : $685)$.

I take it that the 'internal alterations' that involve 'not merely relations, but rather accidents' are alterations of the representations that the soul has, similarly to the $\boldsymbol{M K}_{2}, 28: 758$ passage previously considered. Again, Kant is here expressing something like premise 5 . The two first sentences of the quote obliquely express premises 3-4 as well: 'Bodies as bodies' are bodies as phenomena, and they cannot affect the soul because the 'outer relation in which a body stands with another substance', i.e., influence by means of moving powers, 'can be thought only in space'. As a result, it must be the 'intelligible noumenon' that has influence on the soul.

The fact that Kant talks about 'the soul' in these passages should not mislead us into thinking that he is concerned merely with influence on the noumenal soul (which bodies as 
bodies obviously could not have). His concern is more generally what kind of influence could result in representations, as is clear from the following 1794-95 lecture note:

The community of the soul with the body cannot be thought at all, as long as that which is phenomenon in each is taken; (...) e.g., in regard to pleasure and displeasure, also in regard to the power of imagination (...). [T]he representation (...) is produced in us not by the phenomenon itself of the body but, rather by the substrate of matter $\left(M V_{i}, 29: 1028-1029\right.$, my italics).

In these passages, ${ }^{27}$ Kant expresses his own view rather than Baumgarten's. Baumgarten concurs with the impossibility of empirical affection, but endorses ideal influence and preestablished harmony (cf. Baumgarten 2013: \$448f.) rather than, as Kant does, real influence between noumena as a solution:

To think this influence <influxus> on one another between soul and body materially, and yet so that both would be outside each other, and each for itself, is something in itself impossible: and if one assumes it ideally, then this would be nothing but the preestablished harmony <harmonia praestabilita>, and would no longer be influence <influxus>. It must thus be thought as the immaterial effect of the noumenon of each (MVi, 29: 1029, italics in original; cf. $\mathbf{M M r}, 29: 908){ }^{28}$ 
The line of argument suggested by these metaphysics lectures can be found in $K r V$ as well. I leave aside here the discussion of soul-body interaction in the Fourth Paralogism of the A edition, even though hints of the Causal Power Argument can be found there $;^{29}$ Kant's discussion mainly makes a different point concerning the circularity of assigning empirical objects as causes of our representations, and the passage itself is also somewhat maligned because of its strong phenomenalist flavor and its excision in the B Edition. ${ }^{30}$

Kant holds that psychology, in investigating the 'appearances of our soul', i.e., our Srepresentations, should proceed so that 'empirical laws of corporeal appearances, which are of an entirely different species, will not be mixed up in the explanation of what belongs merely to inner sense' (A683/B711). These empirical laws are the 'laws in accordance with which [alteration of places] is determined (moving powers)' (B66-67), which are of a 'different species', and hence unsuitable for explaining that which belongs merely to inner sense, i.e., non-spatial S-representations. Instead, psychology should proceed as 'a consideration of [the] object of inner sense as a whole (...) [which] will not be mixed up with properties of any different kind' (A683/B711; cf. MD, 28: 682). ${ }^{31}$

In a note to the first edition, at A211, Kant claims that: 'Space makes community possible. Now since the thinking being with all its faculties, whose effects belong merely to inner sense, is not a relation of space, the commercium of the soul with the body is therefore not comprehensible' $(\boldsymbol{N}, 23: 31-32)$. Here we can assume the presence of premises 1-5 in a very truncated form in the claim that 'the thinking being with all its faculties, whose effects belong merely to inner sense, is not a relation of space' - the 'effects' in question here should be understood as the S-representations, which 'belong merely to inner sense' (premise 5), and are not 'in a relation of space' (which is a problem because of premises 3 
and 4). The conclusion, that 'the commercium of the soul with the body is therefore not comprehensible', is recognizably the same as that from the metaphysics lecture where Kant states that 'how this interaction <commercium> is constituted, we do not know' $\left(\boldsymbol{M K}_{2}, 28\right.$ : 758), although Kant does not in this note explicitly affirm NA.

The B Edition of $\boldsymbol{K} r \boldsymbol{V}$ follows the same route to arrive at a resulting endorsement of NA. Towards the end of the B Paralogisms, Kant broaches 'the problem of explaining the community of the soul with the body' (B427). While, he says, a discussion of this problem does not properly belong to the Paralogisms qua criticism of the claims of rational psychology, Kant nonetheless believes that he can offer a 'sufficient reply' (B427) to the problem. He begins in a now familiar way by summarizing the difficulty as involving the heterogeneity between the objects of outer sense, which are in space, and the soul (as object of inner sense) which is only in time:

The difficulty presented by this problem consists, as is well known, in the presumed difference in kind between the object of inner sense (the soul) and the object of outer sense, since to the former only time pertains as the formal condition of its intuition, while to the latter space pertains also (B427).

Kant does not specify why this difference in kind presents a problem. Indeed, the passage by itself can seem to invite a more general interpretation along lines suggested by Ameriks: 'heterogeneous things in themselves cannot interact with each other', ${ }^{32}$ or better (since Kant refers not to things in themselves but to objects of inner and outer sense), that 
heterogeneous things cannot interact with each other. This assertion seems rather unsupported, however, as Ameriks points out; ${ }^{33}$ it would moreover contradict the solution to the Third Antinomy concerning the compatibility of freedom and determinism, which is premised precisely on the view that causal interaction can take place between heterogeneous things, e.g., between the free subject in itself as cause and changes in appearances as effects. ${ }^{34}$ If the explication given in this paper is on the mark, however, Kant's terse statement adumbrates not a general heterogeneity problem concerning 'difference in kind', but a specific one, pertaining to the powers of the objects of outer sense in relation to the soul and its non-spatial inner determinations, i.e., S-representations. This explains why Kant refers to space and time in the passage: The fact that 'only time' pertains to the object of inner sense and its S-representations implies premise 5, while the spatial nature of bodies and their powers (as moving powers) implies premises 3-4.

Together, these generate the Causal Power Argument that results in the denial of empirical affection, hence Kant's suggested solution appeals to the noumenal, to what 'grounds the appearance’:

But if one considers that the two kinds of object are different not inwardly but only insofar as one of them appears outwardly to the other, hence what grounds the appearance of matter as thing in itself might perhaps not be so different in kind, then this difficulty vanishes (B427-428). 
Again, we see that the appeal to noumenal interaction fills in for the lack of interaction between outer and inner appearances, including, I have argued, the notorious affection of the subject resulting in representations.

\section{V: Whither Empirical Affection?}

There are many passages in which Kant seems to affirm empirical affection. ${ }^{35} \mathrm{I}$ cannot here provide a comprehensive discussion of all of these passages. However, unless an alternative way of reading them is at least sketched, the Causal Power Argument threatens to saddle Kant with inconsistent commitments. I will thus propose, with relevant examples, two strategies for reading these passages so as to disavow commitment to empirical affection:

1. Kant may sometimes use 'affection' more broadly than explicated in section I, to mean something like a causal relation between objects and the human being in general, the effect of which need not be limited to representations. This would allow for an innocuous kind of empirical affection: The affection of our (physical) sense organs by other objects in space. Some of the passages where Kant seems to affirm empirical affection can be read as saying not that empirical objects cause representations by affecting us, but rather that they cause changes in our physical sense organs. For instance, when Kant states that 'the light that plays between our eyes and the heavenly bodies effect a mediate community between us and the latter' (A213/B260, my italics), he might refer to physical interaction between our own physical body and other bodies, rather than between bodies and us qua representing subjects. The reference to our physical organ of sight ('our eyes'), and the fact that the 
Third Analogy concerns only the community of substances in space (cf. B256), supports this reading.

2. On many occasions, Kant simply takes for granted that there is interaction between body and soul, while bracketing the issue of how such interaction is possible (whether empirically or noumenally). In these contexts, he speaks nonchalantly of mutual influence between body and soul, without thereby affirming specifically empirical affection. This is often the case in his writings on physiology and anthropology. Similarly, Kant often speaks matter-offactly about teleology and animal mentality, although (as we saw in section II) strictly speaking this should be construed only regulatively. If empirical affection presupposes the life of our own body, as origin of representations (through our sense organs) and governed by representations (through intentional action), it is not surprising if Kant espouses the same regulative stance towards affection.

In $M M r$ Kant asserts that

$[\mathrm{s}$ ]oul and body are in interaction, and this interaction is so strong that even mere thinking already has an influence on the body. The soul works immediately on the nervous system, and the remaining parts of the body are mere instruments through which it works by means of the nervous system. It is the business of anthropology to determine this interaction more closely (MMr, 29: 907).

This passage seems to indicate empirical interaction between thinking and the nervous system. However, in the very next sentence Kant states that ' $[w]$ e consider now (...) the 
possibility of the interaction' (MMr, 29: 907). In explaining this possibility, he reverts to the point that "motion and thinking are so different that one cannot comprehend how the one is supposed to have an effect on the other; but the body is a phenomenon and consequently its properties are as well. We are not acquainted with its substrate' (MMr, 29: 908). Hence Kant shifts the question to the noumenal level, to 'how this [i.e., the substrate] could be in interaction with the soul' (MMr, 29: 908).

Indeed, causal interaction is part of Kant's account of the regulative function of the idea of the soul: One of its properties is 'standing in community with other real things outside it' (A682/B710). By regulatively assuming such causal community, we can investigate inner sense without allowing 'empirical laws of corporeal appearances' to be 'mixed up in the explanation' (A683/B711); similarly, teleology's regulative function obviates misguided constitutive alternatives (like hylozoism). This allows us to speak as if soul and body interact empirically, while respecting the Causal Power Argument.

\section{VI: Conclusion}

I have argued that in the Critical period, Kant rejects empirical affection of the subject by outer objects because of the Causal Power Argument. According to this argument, for us to be affected by an object, that object must have a suitable power for causing the resulting representations. Empirical objects, however, do not have suitable powers; they have nothing but moving powers, and moving powers cannot cause the non-spatial representations resulting from affection. Given that some affection is required, and that 
noumenal and empirical affection are the only two kinds, the denial of empirical affection leads Kant to affirm noumenal affection.

The Causal Power Argument is a rather familiar argument: It resonates with dualistic worries concerning mind-body interaction that occupy center stage in post-Cartesian philosophy. Kant's transcendentally idealist distinction between appearances and things in themselves allows him to give proper weight to considerations both in favor of and against interactionist dualism: Throughout his career Kant consistently maintains an interactionist position on metaphysical grounds (cf. Watkins 1995). However, his Critical framework confirms the kind of worries expressed e.g. by Princess Elisabeth, specified in the Causal Power Argument through an account of physical objects as possessing nothing but moving powers. In denying that these objects are things in themselves, Kant can hold on to interaction, while relegating it to the noumenal realm.

Accepting the Causal Power Argument should lead us to reexamine Kant's repeated claim that he is proposing an empirical dualism (cf. A367, A370, A379; $\mathbf{M M r}, 29: 928 ; \boldsymbol{M D}, 28$ : 680; $\boldsymbol{M K}$, 28: 771; R5653, 18: 309-310). While not perhaps a full-blown substance dualism, Kant at least proposes a dualism with respect to empirical causation: Outer effects have outer causes, while inner effects (i.e., representations) have inner causes. An estimation of the consequences of this fact for the peculiar nature and prospects of Kant's empirical psychology is a topic that awaits further discussion.

Among these consequences may be a reconsideration of the role of regulative ideas in psychology. I have suggested that passages where Kant seems to be talking of empirical affection can be read either as physical interaction between outer objects and our sense organs, or as discussing affection regulatively, while ultimately granting it noumenal status. 
My main aim in the article, however, has been to explicate the Causal Power Argument and show that it can be attributed to Kant. ${ }^{36}$

\section{Bibliography}

Adickes, Erich. (1929) Kants Lehre von der doppelten Affektion unseres Ich als Schlüssel zu seiner Erkenntnistheorie. Tübingen: Verlag von J.C.B. Mohr.

Allais, Lucy. (2004) 'Kant's One World: Interpreting “Transcendental Idealism”. British Journal for the History of Philosophy, 12.4, 655-684.

Allison, Henry E. (1996) Idealism and Freedom. Essays on Kant's Theoretical and Practical Philosophy. Cambridge: Cambridge University Press.

Allison, Henry E. (2004) Kant's Transcendental Idealism. An Interpretation and Defense. Revised and enlarged edition. New Haven and London: Yale University Press.

Ameriks, Karl. (2000) Kant's Theory of Mind. New Edition. Oxford: Oxford University Press.

Ameriks, Karl. (2011) 'Kant’s Idealism on a Moderate Interpretation’. In Dennis Schulting and Jacco Verburgt (eds.), Kant's Idealism. New Interpretations of a Controversial Doctrine (Dordrecht-London: Springer), pp. 29-53.

Aquila, Richard. (1982) 'Is Sensation the Matter of Appearance?’ In Moltke S. Gram (ed.), Interpreting Kant (Iowa City, IA: University of Iowa Press), pp. 11-19. 
Baumgarten, Alexander. (2013) Metaphysics. A Critical Translation with Kant's

Elucidations, Selected Notes, and Related Materials. Courtney D. Fugate and John Hymers (trans. and eds.). London: Bloomsbury.

de Boer, Karin. (2014) 'Kant's Multi-Layered Conception of Things in Themselves, Transcendental Objects, and Monads'. Kant-studien, 105.2, 221-260.

Descartes, René (1984-1991). The Philosophical Writings of Descartes, 3 vols., trans. John Cottingham, Robert Stoothoff, Dugald Murdoch, and Anthony Kenny. Cambridge: Cambridge University Press.

Falkenstein, Lorne. (1990) 'Kant's Account of Sensation'. Canadian Journal of Philosophy, 20.1, 63-88.

Falkenstein, Lorne. (1995) Kant's Intuitionism: A Commentary on the Transcendental Aesthetic. Toronto: University of Toronto Press.

Gram, Moltke S. (1985) The Transcendental Turn. Gainesville, FL: University of Florida Press.

Hall, Bryan. (2010) 'Appearances and the Problem of Affection in Kant'. Kantian Review, $14.2,38-66$.

Hennig, Boris. (2011) ‘Kant's Modell kausaler Verhältnisse. Zu Watkins' Kant and the Metaphysics of Causality'. Kant-studien, 102.3, 367-384.

Henschen, Tobias. (2014) 'Kant on Causal Laws and Powers'. Studies of History and Philosophy of Science, 48, 20-29. 
Hogan, Desmond. (2009) 'Noumenal Affection’. Philosophical Review, 118, 501-532.

Kalter, Alfons. (1975) Kants vierter Paralogismus. Meisenheim/Glan: Anton Hain.

Kant, Immanuel. (1900-) Kants gesammelte Schriften. Edited by the Akademie der

Wissenschaften. Berlin: Walter de Gruyter.

Kant, Immanuel. (1987) 'Eine neu aufgefundene Reflexion Kants „Vom inneren

Sinne“ (Loses Blatt Leningrad 1)'. Reinhard Brandt (ed.), Kant-forschungen, 1, 1-30.

Kant, Immanuel. (1992-) The Cambridge Edition of the Works of Immanuel Kant. Edited by Paul Guyer and Allen Wood. Cambridge: Cambridge University Press.

Kitcher, Patricia. (2010) Kant's Thinker. Oxford: Oxford University Press.

Langsam, Harold. (1994) 'Kant, Hume, and Our Ordinary Concept of Causation’.

Philosophy and Phenomenological Research, 54.3, 625-647.

Langton, Rae. (1998) Kantian Humility. Our Ignorance of Things in Themselves. Oxford:

Clarendon Press.

Nitzan, Lior. (2010) 'The Thought of an Object and the Object of Thought: A Critique of Henry E. Allison’s “Two Aspect” View'. Archiv für Geschichte der Philosophie, 92, 176198.

Piché, Claude. (2004) 'Kant and the Problem of Affection’. Symposium, 8.2, 275-297.

Pollok, Konstantin. (2006) 'Kant's Critical Concepts of Motion'. Journal of the History of Philosophy, 44.4, 559-575. 
Powell, C. Thomas. (1988) 'Kant's Fourth Paralogism'. Philosophy and Phenomenological Research, 48.3, 389-414.

Robinson, Hoke. (1994) 'Two Perspectives on Kant's Appearances and Things in Themselves'. Journal of the History of Philosophy, 32.3, 411-441.

Sellars, Wilfrid. (1967) 'Some Remarks on Kant's Theory of Experience'. The Journal of Philosophy, 64.20, 633-647.

Stang, Nicholas. (2015) 'Who’s Afraid of Double Affection?' Philosophers' Imprint, 15.18, $1-28$.

Vaihinger, Hans. (1881-1892) Commentar zu Kants Kritik der reinen Vernunft. 2 vols. Stuttgart: W. Spemann.

Watkins, Eric. (1995) 'Kant’s Theory of Physical Influx'. Archiv für Geschichte der Philosophie, 77.3, 285-324.

Watkins, Eric. (2004) 'Kant’s Model of Causality: Causal Powers, Laws, and Kant's Reply to Hume'. Journal of the History of Philosophy, 42.4, 449-488.

Watkins, Eric. (2005) Kant and the Metaphysics of Causality. Cambridge: Cambridge University Press.

Watkins, Eric. (2014) 'Efficient Causation in Kant'. In Tad M. Schmaltz (ed.), Efficient Causation: A History (Oxford: Oxford University Press), pp. 258-282.

Westphal, Kenneth. (2004) Kant's Transcendental Proof of Realism. Cambridge: Cambridge University Press. 
' References to Kant's works give the Akademie Ausgabe volume and page, except the Kritik der reinen Vernunft where I use the standard A/B edition pagination. Exception is the 'Leningrad Reflexion', where I refer to the transcription published in Kant-Forschungen. Translations are from the Cambridge Edition of the Works of Immanuel Kant, or, where unavailable, my own. Specific texts are abbreviated as follows:

Anth: Anthropologie in pragmatischer Hinsicht

EB: Einige Bemerkungen zu Ludwig Heinrich Jakob’s Prüfung der Mendelssohn'schen Morgenstunden

EE: $\quad$ Erste Einleitung in die ,Kritik der Urteilskraft

FM: $\quad$ Preisschrift über die Fortschritte der Metaphysik

KrV: $\quad$ Kritik der reinen Vernunft

KU: $\quad$ Kritik der Urteilskraft

LK: Gedanken von der wahren Schätzung der lebendigen Kräfte

LR: $\quad$ Leningrad Reflexion, Vom inneren Sinne

MAN: Metaphysische Anfangsgründe der Naturwissenschaft

MD: Metaphysik Dohna

MK: Metaphysik $\boldsymbol{K}_{2}$

MLi: Metaphysik $L_{l}$

ML: $\quad$ Metaphysik $L_{2}$

MMr: Metaphysik Mrongovius

MS: Metaphysik der Sitten

MVi: Metaphysik Vigilantius

MVo: Metaphysik Volckmann

N: $\quad$ Nachträge zur ,Kritik der reinen Vernunft' (1. Auflage)

ND: Principiorum primorum cognitionis metaphysicae nova dilucidatio 
Prol: Prolegomena zu einer jeden künftigen Metaphysik, die als Wissenschaft wird auftreten können

R: Reflexionen

Sö: $\quad$ Anhang zu Sömmering’s, Über das Organ der Seele‘

$\ddot{U E} \quad \quad \ddot{U} b e r$ eine Entdeckung, nach der alle neue Kritik der reinen Vernunft durch eine ältere entbehrlich gemacht werden soll

${ }^{2}$ These three possibilities are famously delineated as a 'trilemma' by Hans Vaihinger (1892: 52-53). The contemporary debate still uses Vahinger's trilemma as a touchstone, cf. e.g. Allison (2004: 6566); Hall (2010: 38); Stang (2015); Piché, (2004: 275); Kitcher (2011: 203-204); Westphal, (2004: 38-39).

${ }^{3}$ See e.g. Hogan (2009) for NA; Nitzan (2010) for EA; and Stang (2015) for DA.

${ }^{4}$ Cf. Langsam (1994); Langton (1998); Watkins (2004), (2005), and (2014). See also Henschen (2014).

${ }^{5}$ In the following, I leave the topic of self-affection aside, and will thus be concerned only with the affection by outer objects. For brevity, I refer simply to 'empirical objects' rather than 'empirical outer objects' in the remainder of the article.

${ }^{6}$ Or more precisely, it implies that no causal influence on us by empirical outer objects is possible. Considering the opposite direction is tricky, among other things because the extent to which the empirical self can be ascribed causal powers at all is controversial. My focus in this article will be solely on the subject-directed part of the subject-object causal interaction, i.e., the affection of the subject by the object.

${ }^{7}$ See e.g. Hogan (2009); Piché (2004); Westphal (2004).

${ }^{8}$ Allison (2004: 64). Cf. Gram (1985: 41f.).

${ }^{9}$ See e.g. Stang (2015); Hall (2010: 45); de Boer (2014: 231-232); Hogan (2009: 514f.); Piché (2004); Kitcher (2011: ch. 12); Westphal (2004: 38f.). 
${ }^{10}$ Watkins defends this account at length in his (2004) and (2005). For criticism of Watkins' view, cf. Hennig (2011).

${ }^{11}$ Translation of Kraft modified from 'force' to 'power'. In the following, I will stick to 'power' as a translation of $K r a f t$, and alter translations accordingly.

${ }^{12} L K, \$ \S 5-6,1: 20$, cf. $N D, 1:$ 415-416; see further Watkins (2005: 106-108).

${ }^{13}$ Kant's position here resembles Descartes', who writes in his famous response to Gassendi concerning soul-body interaction: 'The whole problem contained in such questions arises simply from a supposition that is false and cannot in any way be proved, namely that, if the soul and the body are two substances whose nature is different, this prevents them from being able to act on each other' (Descartes 1984-1991: vol. II, 275). A letter to Princess Elisabeth diagnoses the source of the problem: 'I think that we have hitherto confused the notion of the soul's power to act on the body with the power one body has to act on another' (Descartes 1984-1991: vol. III, 219). In LK, Kant similarly claims that understanding power as such in terms of physical motion leads to difficulties, and that 'both difficulties [of the influence of soul on body, and body on soul] disappear, however (...) when the power of matter is ascribed not to motion, but rather to its actions on other substances, actions that must not be further determined' ( $L K, \$ 6,1: 20)$.

${ }^{14}$ It may seem that NA has no advantage over EA on this point, since noumenal powers are equally unknowable. However, this overlooks the inherent imbalance between the two kinds of claim: Unlike noumenal claims, valid empirical claims require objective reality. If we can only think, but not experience, powers through which objects affect us, this amounts to a confirmation of NA, not evidence that NA and EA are on a par as hypotheses.

${ }^{15}$ Kant's discussion of organized beings focuses on the power to cause motions on the basis of one's representations, but the status of such a power could presumably be transferred to the converse power to have representations caused by the motions of one's sensory organs. 
${ }^{16}$ Kant also occasionally talks of motion in a different sense, namely as motion of the subject, rather than of an object. Cf. B155n., see further Pollok (2006). However, this sense is not relevant here.

${ }^{17}$ Cf. e.g. B164, A191/B236, A250, A370f., A375, A386f., A490-491/B518-519, A494/B523, A498/B527; $\boldsymbol{E E}, 20: 209$. The discussion of these 'appearances are mere representations' passages in the literature is vast and complex; representative contributions are Robinson (1994); Allison (1996: 12-13); Allais (2004).

${ }^{18}$ As Ameriks (2011: 30) says, they are 'merely subjective in an individual, psychological, and occurrent sense'.

${ }^{19}$ Cf. e.g. the representing/represented distinction in Sellars (1967). Note, however, that what is represented by an S-representation might be another S-representation (cf. e.g. A108, A189/B234); but what is represented by an S-representation can be something that is not itself an Srepresentation, for instance an empirical object in space.

${ }^{20}$ This is brought out more clearly in some of Kant's later Reflexionen on the topic, especially R5653, 18: 306-312, where Kant states: '[N]ot everything that is in time is also in space, e.g., my representations' (18: 309).

${ }^{21}$ Cf. also $M M r$, 29: 876, 29: 905-906; MVo, 28: 449; MVi, 29: 1028.

${ }^{22}$ Note that the 'virtual presence' (MMr, 29: 909; MD, 28: 685-686; $M K_{2}, 28: 757 ; M V$; 29: 1029)

of the soul and its representations in space does not help here: Moving powers are powers to cause changes in spatial relations, not changes in what is virtually present there.

${ }^{23}$ See Aquila (1982).

${ }^{24}$ This is not to say that only sensations as 'merely subjective representations' are S-representations. I take it that insofar as all representations belong to inner sense, as Kant often states (cf. A34/B50, A98-99, A101, A138/B177, A155/B194, A177/B220, A197/B242), all the kinds of representation mentioned by Kant e.g. in the A320/B376 Stufenleiter passage might be S-representations. This is not, however, directly relevant to the Causal Power Argument. 
${ }^{25}$ Cf. Falkenstein (1990) and (1995: 119f.), who argues that sensations are 'physical states of the nervous system in the sensing subject' (1995: 123).

${ }^{26}$ Hogan (2009: 525fn60). Powell (1988: 409) notes that 'talk of causal interaction is appropriate within the framework of outer sense, where all effects are changes of location, or within the framework of inner sense, where all effects are (non-spatial) thoughts, but (...) it is incoherent to speak of causes within one of these frameworks having effects in the other'. He also sees that Kant appeals to noumenal influence as a result. However, he does not explicate why this is the case, or relate it to Kant's theory of affection. Ameriks (2000: 89f.), also notes some of these passages; I discuss his reading briefly below.

${ }^{27}$ Cf. also $M M r$, 29: 907-909; R5984, 18: 416.

${ }^{28}$ 'Immaterial' here simply means that the effect is not ascribable to matter in space, but does not imply any positive cognition of what it is.

${ }^{29}$ Especially the following: 'What appears as matter could not, through its immediate influence, be the cause of representations, since these are an entirely heterogeneous species of effects' (A390). However, this line of argument is put into the mouths of adherents to systems of 'preestablished harmony' and 'supernatural assistance' (A390), and it is not clear whether Kant intends to endorse the argument himself. In the sentences that follow Kant seems instead to be making a different point against empirical affection, namely that it would be viciously circular.

${ }^{30}$ Cf. Kalter (1975). A passage from the A Fourth Paralogism raises a potential problem for the Causal Power Argument, as Kant seems to claim that empirical mind-body interaction is unproblematic since both mind and body are 'mere representations': 'As long as we keep inner and outer appearances together with one another, as mere representations in experience, we find nothing absurd and nothing that makes the community of both modes of sense appear strange' (A386). My response is that Kant is in all likelihood not affirming interaction in this passage; in the Third Analogy Kant discusses an ambiguity in the term 'community', where it 'can mean either 
communio or commercium' (A213/B260). Both signify the membership of parts in a common whole, but only the latter signifies dynamical community, i.e., causal interaction between the parts. I take it that the Fourth Paralogism passage refers to the communio, rather than the commercium, between both modes of sense. This can be supported by first of all noting that Kant immediately before the above cited passage says that he is now only dealing with the question of 'the conjunction [Verknüpfung] of representations in inner sense with the modifications of our outer sensibility, and how these may be conjoined with one another according to constant laws, so that they are connected into one experience' (A386), which would appear to be a question of the conjoining of different representations in one unified experience, rather than the causal interaction between these representations. This also accords with the passage from the Third Analogy, where Kant says that 'in our mind all appearances, as contained in a possible experience, must stand in a community (communio) of apperception' (A214/B261). Second, it would be surprising if Kant were talking about a commercium here, since only a page later he states categorically that it is not the motion of matter that causes representations in us' (A387), and later in the Paralogism that 'it would never occur to anyone to take as an external cause what he has already recognized as a mere representation' (A390). Neither of these claims seem consistent with a commercium between inner and outer appearances.

${ }^{31}$ Hence the dependence of inner experience on outer experience in general, established in the Refutation of Idealism (B274-279), should not (and need not) be read as establishing necessary causal connections between objects of inner experience and objects of outer experience.

${ }^{32}$ Ameriks (2000: 89).

${ }^{33}$ Ameriks (2000: 90f.).

${ }^{34}$ Cf. A530/B558f. For an argument that an appreciation of this point can help solve the problem of noumenal affection, see Piché (2004). 
${ }^{35}$ Cf. e.g. A28, B208, A168/B210, A213/B260; MAN4: 476; Anth \$§15-23, 7: 153-161; KU, 5: 224. See further Adickes (1929: 5-15).

${ }^{36}$ I would like to thank Houston Smit for initial discussion and encouragement, and Karin de Boer, Hege Dypedokk Johnsen, Toni Kannisto, Hedda Hassel Mørch, Camilla Serck-Hanssen and anonymous referees for invaluable comments on earlier drafts of this paper. 